\title{
The Tradition of Ancestor Worship in Vietnamese Families from the Beginning to the Present Day and Some Current Problems
}

\author{
Tran Van Huan* \\ Deputy Dean, Faculty of Sociology and Development, Academy of Politics Region II, Ho Chi Minh City, \\ Vietnam
}

*Corresponding Author: Tran Van Huan, Deputy Dean, Faculty of Sociology and Development, Academy of Politics Region II, Ho Chi Minh City, Vietnam

\begin{abstract}
Based on the achievements of previous studies, both in Vietnam and foreign countries, the paper contributes to the understanding of one of the most important cultural behavior between the living and the dead, i.e. the tradition of ancestor worship. To shed light on this topic, the author carried out in-depth analysis of three main aspects: the origin of the tradition of ancestor worship, the practice of ancestor worship in Vietnamese families in the traditional agricultural society, and current problems that need attention regarding the tradition of ancestor worship in the context of current industrialization and urbanization
\end{abstract}

Keywords: ancestor worship, families, Vietnamese people.

\section{INTRODUCTION}

The tradition of ancestor worship is one of elements that create culture of families, clans and the entire nation in general, so it involves many issues. According to a study conducted by the ethnologist Dang Nghiem Van (2002), this type of belief is understood in both broad and narrow sense. In broad sense, it is the worship of the people having contribution to their village, local community and nation. In a narrow sense, it refers to the worship of the deceased blood relatives to meet the functions of reflecting and strengthening of clans. In the same way, the authors Cao Van Thanh and Trinh Thi Thuy (2006) divide this custom into 4 levels: (1) Worship Hung king as a national deity (2) worship founders of a craft or people who discovered new lands to establish villages and fought foreign enemies; (3) worship ancestors of clans; (4) worship deceased family members

In order to contribute to the understanding of the family culture of Vietnamese people from the beginning to the present, the author only studied the tradition of ancestor worship of deceased blood relatives according to the classification of Dang Nghiem Van or worship ancestors of clans or deceased family members based on the classification of Cao Van Thanh and Trinh Thi Thuy through manifestations in funeral rites, building tombs and making sacrifices. Based on the success of previous studies, including studies of both Vietnamese and foreign authors, the article focuses on the following basic topics: origin, practice, conception and influences of ancestor worship on human life and society, especially in contemporary times.

\section{DATA AND RESEARCH METHODS}

Since 1913-1914 when Phan Ke Binh wrote Vietnamese customs and published each issue in the Journal of Indochina, the study of ancestor worship in our country has been conducted for over 100 years. In addition, our country is a multi-ethnic nation, in which Viet-ethnic group make up the majority, and the research sources on ancestor worship in our country are plentiful. Within the scope of this article, we focus on analyzing Vietnamese custom of worship of ancestors, more precisely, ancestor worship at the scope of Vietnamese families.

The research sources on ancestor worship in Vietnamese families can be divided into two types: the first is the research of Vietnamese authors and the second is the research of foreign authors. The latter can be divided into two smaller categories: studies conducted before August Revolution in 1945 by French missionaries, scholars and rulers in Vietnam, and studies carried out by scholars, scientists 
from many different countries coming to Vietnam for studying or attending seminars on Vietnam studies. Research approaches are also diversified. There are authors from the perspective of history, religion or folklore. Others consider this issue on the basis of psychology, anthropology or sociology. Regarding research methods, while some researchers only use quantitative methods, others use qualitative method or they mix qualitative and quantitative one. Some researchers only explore ancestor worship by the features that have been shaped in history, while many researchers pay attention to the practice and transformation of this custom as well as the socio-economic condition leading to that practice and transformation. From the plentiful sources of both content and approaches, the author of this article has tried to analyze and synthesize them to provide a relatively systematic understanding of the practice and transformation of this tradition in Vietnamese families from the beginning up to now.

\section{THE ORIGIN OF THE TRADITION OF ANCESTOR WORSHIP OF VIETNAMESE PEOPLE}

The tradition of ancestor worship of Vietnamese people stems from the conception of the relationship between the living and the dead. In ancient folk beliefs, Vietnamese people have the conception that there is birth, existence, there is also death, so "life or death is due to the fate", "life is temporary, and death is eternal" or "death is the end". Researcher Dang Duc Sieu (2006, pp.383-384) cited the verse "the body is dead, the soul is still alive" in Kieu's poem of Nguyen Du to illustrate this conception. The author believes that this verse reflects the conception of the relationship between the soul and body in human life. Accordingly, when one lives, the soul (the spirit) and the body are gathered together in a unified entity. When one dies, only the body dies, but the soul leaves the body to live in an invisible world, next to people who are living. Dang Duc Sieu said that this primitive belief, through cultural exchanges, later has been added the conception of "death as birth", "death as existence" in Confucianism to form the tradition of ancestor worship in Vietnamese families. In the work "Historical Outline of Vietnamese Culture", Dao Duy Anh (2000) also said that according to Vietnamese folk beliefs, people have both the soul and the body. When people die, their soul will leave the body and become a ghost, but they still take care of their descendants. When there is something dangerous, their soul will alert their children and grandchildren to be aware of. Because ancestral souls are so closely connected to their descendants, descendants must worship ancestors. Those who do not worship their ancestors so that their ancestors have to become miserably hungry souls are considered extremely undutiful. Therefore, worshipping ancestors is more important than showing gratitude to parents who give birth to and nurture us.

Not only Vietnamese researchers, but many foreign authors also share the same opinion when studying about Vietnam. For example, from the beginning of the twentieth century, in the work family and religion in Annam (1930), Western missionary L. Cadière stated: "All ancestors of the family are still here. The folk call people who died by the names 'the dead' or 'the lost,' but their souls dwell on the altar forever". Another author, E. Diguet, (as cited in Nguyen Thua Hy, 2011, pp.260-261) in the work Annam people: society, customs and religion (1906) also asserted that "The living have been ruled by the dead". Recently, in an article written for the International Conference on Vietnam studies, co-organized by Ho Chi Minh National University and University of Toronto (Canada) in Binh Chau in December 2007, the Dutch anthropologist Oscar Salemink (2010, p.12) also affirmed: "In the dominant cosmology in Vietnam, death is a journey rather than a radical departure, which means that the souls of the dead continue to be with us for some time. In the main religious traditions including Buddhism, Taoism, Confucianism, ancestor worship and spirit worship, death is a transition of the soul from one world to another world where the soul lives on as a spirit until s/he is born again".

It should be emphasized that the conception of the soul of the dead continues to exist alongside the living is not entirely unfounded, but it comes from the real life of the people. Many people meet their lost loved ones through dreams, or they receive certain signals through foreshadowing. The historian Nguyen Thua Hy (2011) argued that the real life also forms a mysterious communication channel between the dead and the living. As an intermediary for the communication channels are the contingent of powwow, fortune tellers, worshippers, mediums, and currently supplemented by "psychic". According to L. Cadière "The belief in the afterlife of Vietnamese people is not imposed as the object of faith. It is recognized as the visible and testable result of an experimental knowledge, so there is nothing supernatural and mysterious in it. It is believed that the dead still live near the living, as one believes in the sunlight or the weight of the plummet" (Nguyen Van Huyen, 2015, p.105). 
Therefore, ancestor worship originated from the real life, not from any vague or irrational faith. Behavior between the living and the dead is performed in such a sincere way that helps to solve the objective problems posing from the life. On the one hand, funerary rites shows appropriate grief for the deceased, on the other hand, they are also a form of calming the souls of ancestors so that they are guided safely on the journey to the other world - safely out of reach of humans and not to become revengeful wandering souls (Salemik, 2010, p.12). Due to these practical goals, ancestor worship in Vietnamese families was formed and existed throughout the long history of the nation.

\section{THE TRADITION OF ANCESTOR WORSHIP OF VIETNAMESE FAMILIES THROUGHOUT THE HISTORY}

In the speeches at the Scientific Conference on ancestor worship in contemporary society which was held in Viet Tri on Hung King's death anniversary in April 2013, many international delegates affirmed that ancestor worship has long existed and developed throughout the history (Chu A \& Truong Chan Vi, 2013). This practice has even been a common feature of human civilization since prehistoric times (Mancacaritadipura, 2013). In Vietnam and China, "In the period before Confucius was born, there had been books talking about events related to sacrifices and ancestral worship. In each house, there is place for worshipping ancestors and an altar is placed inside the house" (Tran Le Bao, 2013, p.74). It is the agricultural tradition with two main activities including cultivation and animal husbandry and the main role of men in the family in producing and inheriting assets that forms the basis of ancestor worship established according to paternal lineage (Le Duc Hanh, 2013, p.239). Thus, the tradition of ancestor worship in Vietnam in general as well as in Vietnamese families in particular has had a long history of thousands of years.

So what made persistent and powerful strength in the tradition of ancestor worship. So far, there have been many different explanations, but what accepted by most people is that the soul of the deceased continues to dominate the living. According to Father L. Cadière, that domination includes two aspects: blessing and bringing calamity. He said, "It is often thought that the deceased will do good things for the people who are living in the family when the living perform their duty of filial piety. On death anniversaries or festivities, the ancestors were provided with what they need, feeling happy and peaceful, and in turn showing their presence by giving all the good to their descendants. But if descendants choose a bad place to build a grave, or they forget to worship or make cautious offerings, the ancestors will punish them. Therefore, according to the instructions of the worshipper, they must move the remains and make an apology to the displeased ancestors" (Nguyen Van Huyen, 2005, pp.103-104). This is not only a conception but also a custom, an attitude and behavior in the life of Vietnamese families.

The research conducted by Oscar Salemink (2010, p.14) also pointed out the risks "For living relatives or descendants who cannot meet the ritual requirements of a proper burial, the continued presence of a family member wandering as a restless, hungry soul between two worlds is not just a source of existential anxiety in terms of not being able to pay the filial debt. It is a source of profound insecurity and uncertainty regarding the present situation. Health, wealth and good fortune are transient, ephemeral and at constant risk of losing - a risk which will loom large if posed by a malevolent spirit and which undermine confidence in the present and the future"

Besides, ancestor worship also has a great meaning to the living. In the work "Vietnamese Civilization" published in French, Nguyen Van Huyen (2005, p.106) asserted that: "The worship of ancestors, understood as a link binding all members of the family. In the death anniversaries as well as the festivities, people of different branches of a clan gather at the clan temple. If the clan is big, that is, each branch is a complete family with children married and have their own home, this is the unique occasions for members of the big clan to meet each other. In these meetings, natural affection of members of the family is restored or strengthened. It forms a natural binder of the family".

Researcher Doan Van Chuc also appreciated the social impact of the cultural behavior on the deceased, and further clarified the value perspective for each social group. "In any anniversary of a family or clan, all members gather to express the value of the group they constitute and belong to. Hence, social coherence is reestablished and suspect, and conflict may be alleviated or even diminished" (Doan Van Chuc, 1997, p.133). In short, each anniversary and ancestor-worshipping day is an occasion for the unity of the family and clan to be improved, so the cohesion of the family and 
clan is strengthened. Looking at the issue more generally, Vu Tu Lap and his colleagues in the work "the Red River Delta Culture and Population" argued that worshipping and celebrating death anniversaries were actions of connecting the past with the present, or more accurately exploiting the power of the past in order to serve the present. They state that "In those days, the ancestors were invited to testify for deeds and to listen to their children's prayers in order to help them. Ancestors are not just those who were dead, but those who surround, guide and support their descendants. The significant points of the tradition of ancestor worship are revealed when they merge the past into the present, transform the past power to integrate into the modern time and connect ancestors' strength with the life of their descendants" (Vu Tu Lap et al, 1991, p.176).

But every social phenomenon has pros and cons. Along with advantages, the tradition of ancestor worship also has many disadvantages. In the work "Vietnamese customs", Phan Ke Binh noted that "Sacrifices offered are not costly, but many families become miserable because of the death anniversaries. Moreover, siblings may criticize each other for unequal contribution to ancestor worship". Agreeing with Phan Ke Binh's opinion, when talking about the "disadvantages" of ancestor worship in Vietnamese families, Nguyen Van Huyen (2005, pp.104-105) also stated that ancestor worship does not require "precious foods, or burning a lot of joss paper. What is required in ancestor worship is descendants' sincerity". Moreover, he wrote: "in the conception of Vietnamese people, a filial son is not a person who makes a lot of offerings to his parents, but a honest man, a good person, a good student, a good husband, a good father and a good friend. What the ancestors needed would not be the material to feed the bodies of the living, but their names and souls would not be tarnished by the unworthy attitude of their descendants", Nguyen Van Huyen (2005, pp.104-105)

\section{ANCESTOR WORSHIP IN VIETNAMESE FAMILIES NOWADAYS AND PROBLEMS}

Since 1975, especially since Doi Moi (1986), along with the economic achievements, there have been new developments in cultural and spiritual life of the people including ancestor worship. Commenting on this, scholar Vu Khieu (1996: 8) wrote: "From peace was restored, everywhere in the country, especially in recent years, the issues of clans are particularly concerned. Almost every family has incense holders to worship ancestors. Family temples and graves are repaired. Family annals are rediscovered, recorded and disseminated. Due to emotional needs, people in a family or clan visit each other more often. The festivities or the death anniversaries attract attention of many people in the family and clan".

The evidence for $\mathrm{Vu}$ Khieu's general judgment is the results of an empirical research in many regions of the country, with many different social groups. According to the survey data of the Institute for Religious Studies conducted between the late years of the 20th century and the beginning of the $21 \mathrm{st}$ century, the average percentage of Vietnamese families performing ancestor worship reaches $98 \%$ (Le Duc Hanh, 2013, p.245). This absolute proportion was not only concentrated in the Red River Delta but also in the Mekong Delta as a new land. Here, people think that ancestor worship is a "compulsory custom", "the duty and responsibility of the children to the dead" (Bui Thi Hoa, 2013, p.296). The popularity of this custom is not only found among agricultural residents and people living inland, but also among fishermen living on the islands. A case study conducted on Quan Lan Island, Van Don District, Quang Ninh Province shows that on the 30th, 1st and $14^{\text {th }}$ of lunar months, every household here performs a ceremony to worship ancestors to pray for a good health and a lot of fish (Dam Thi Uyen \& Nguyen Thanh Thuy, 2009, p.49). An investigation carried out by Trinh Thi Minh Duc and Luu Ngoc Thanh (2013, p.169) in Thach Bich village, Bich Hoa commune, Quoc Oai district, Hanoi also revealed that most Catholic families put ancestral altars in the most solemn place in their house and the heart and mind of believers all turn to their ancestors, remembering the merits of the previous generations and praying for the souls of the deceased ancestors to go to the heaven. In a psychological study conducted by Nguyen Hoi Loan (2006), the results showed that out of 300 people interviewed, $48 \%$ considered ancestor worship to be very important, 42.3\% considered it important, 9.7\% considered it "neutral" and nobody considered it "unimportant". And the motivation to ancestor worship is shown as follows: expressing gratitude to the previous generations accounts for $96.6 \%$; showing responsibilities and duties of descendants takes 82.6\%; hoping to bless and protect takes 95.3\%; wishing good luck and happiness accounts for 96\%; expecting mental comfort takes 91.3\%; encouraging good and avoid evil takes 78.7\% (Nguyen Hoi Loan, 2006, pp.16-19). 
However, compared to the previous historical periods, including the subsidized period, it can be easily seen that ancestor worship has had many innovations, with a broader social sense. The results of Luong Van Hy (1994, p.460)'s study carried out in Hoai Thi village, Bac Ninh in 1987-1991 showed that on the altar of many families, besides the tablets of previous generations of the family, a photo of President Ho Chi Minh was seen. This is indeed a beautiful cultural pattern expressing both national identity and the spirit of our times. Along with the addition of new elements, many cumbersome and complicated rituals of worshipping have been changed in the direction of simplification and progress. For example, in recent years at a funeral in Dong Ky village, Bac Ninh, people have abandoned the practice of sons wearing straw hats, and banana belts and walking with sticks. Only near relatives wear white mourning towels on their head while distant relatives wear black tapes on their chest or their sleeves and neighbors also wear black bands as prescribed. The dead are allowed to stay in the house for only 24 hours before taking burial to ensure hygiene (Le Hong Ly et al, 2000, pp.63-64).

In addition to positive and progressive changes, the practice of ancestor worship is also revealing aspects against the attributes of a fine custom and hindering the social development.

Firstly, the communal rituals are increasingly strengthened and more and more money is spent on feasts (Kleinnen, 2007, pp.227-231). Regarding the scale of the feasts, during fieldwork in Hoai Thi village Bac Ninh, Luong Van Hy (1994, p.461) noted that there were usually 60 to 120 people eating and drinking on the same anniversary while the entire village has only 761 people. The author stated that when families have a lot of members, death anniversaries will become a financial burden for them. In a study conducted in Hoai Thi village, Luong Van Hy (2013, p.60) said: "The death anniversaries in Hoai Thi have had big changes over the past few decades, stemming from the need to consolidate or strengthen social capital of households". However, there are also many families that take death anniversaries as occasions for them to show off something. Holding death anniversaries perfunctorily has lost the profound meaning in the spirit of family and caused the inappropriate awareness for later generations, so many young people today still mistakenly believe that death anniversaries provide occasions for them to carouse (Pham Con Son, 2010, p.144)

Secondly, in recent years in the mass media as well as in the public opinion in general, people also talk about the shortcomings of family culture and clans including ancestor worship. Not only were big feasts, but it were also the contention between members of a clan about the construction of graves or the dispute between villages over ownership of the cemetery land. Only in the scope of families and clans, ancestor worship also raises many issues that need to be concern. For example, in the sociological survey conducted by Bui Phuong Linh (2016, p.54) in Thi Cam village, Xuan Phuong ward, Tu Liem, Hanoi, when asked about the advantages of ancestor worship, $13.2 \%$ of the respondents said that the gathering of many people in the death anniversaries was not suitable for small houses; $8.2 \%$ of them said that the burning of joss paper causes environmental pollution; $15.5 \%$ said there were too many death anniversaries, affecting the work of descendants; $10.9 \%$ said that unequal contributions caused disunity among siblings; $24.1 \%$ said that the heavy drinking in the death anniversaries caused conflicts in families.

Thirdly, the top disadvantage of ancestor worship is the issue of protecting the ecological environment and sustainable development. Due to the speed of urbanization and population growth, the living space is increasingly shrinking, which forces people to face two options: burying for the deceased according to traditional customs, or brought them into cremation center. For worshipping, they should set up an altar at their home as before, or move it to a collective place for worshipping. The survey data of Bui Phuong Linh (2016, p.54) in Thi Cam village (Hanoi) also showed that $35.9 \%$ of households with graves moved away due to urban planning; $26.4 \%$ said that the local area is lacking land to build graves; $9.5 \%$ said that the current graves are too close to the houses, causing environmental pollution and $28.2 \%$ cannot afford to build the graves. It is clear that the current process of rapid industrialization and urbanization has a strong influence on the practice of ancestor worship in Vietnamese families, which makes many people feel confused, or even mentally unstable. Indeed, there are many problems posing for the practice of ancestor worship in Vietnamese families nowadays.

\section{Conclusion}

The tradition of ancestor worship in Vietnamese families appeared very early in history and has its roots in real life, resolving the objective problems posed from the life to express grief for the deceased 
as well as to pray for aid for the living. This is not only the story of each family or clan, but also the common responsibility of the whole society, including the contingent of scientists. In terms of science, despite the great efforts of individuals as well as scientific agencies, so far, there has been a gap between the knowledge accumulated about ancestor worship and the operation of this practice in real life. As Japanese author Suenari Michio (2010, p.103) states: "Regarding ancestor worship in Vietnam, most of the discussion so far has been on an ideological level, we are lack of information to know how ancestors are being worshiped in reality". So one of the most important tasks in scientific research today is to shorten or to close the gap between science and life. Or as Suenari Michio said that it is necessary to link the discussion on "the thought level" with the "facts" that are happening "in reality". Only then can we provide scientific arguments so that the authorities can devise policies to guide the operation and transformation of ancestor worship in accordance with the needs and aspirations of the people in the near future. It is a practical action that contributes to the cause of building "an advanced Vietnamese culture imbued with national identity" set by the Party and the State.

\section{REFERENCES}

[1] Chu A \& Truong Chan Vy (2013). Discussing the custom of ancestor worship among Chinese Thai people on sociological and religious perspectives, a case study of the worship of house deities and the guardian deities of the Thai people in the Manhai district of Xishuangbana area. Beliefs of Ancestor Worship in Contemporary Society, pp. 31-41. Vietnam Institute of Culture and Arts. Hanoi: Culture and Information publisher

[2] Dao Duy Anh (2000). An outline history of Vietnamese culture. Hanoi: Culture and Information publisher.

[3] Tran Le Bao (2013). The tradition of ancestor in Vietnam and China. In Vietnam Institute of Culture and Arts (Ed.). Ancestor worship in contemporary society. Pp.71-86. Hanoi: Culture and Information publisher.

[4] Phan Ke Binh (1990). Vietnamese customs. Dong Thap: Dong Thap General Publishing House.

[5] Doan Van Chuc (1997). Sociological culture. Hanoi: Culture and Information Publisher.

[6] Trinh Thi Minh Duc \& Luu Ngoc Thanh (2013). Ancestor worship in the Catholic family (case study of Thach Bich village, Bich Hoa commune, Quoc Oai district, Hanoi). In Vietnam Institute of Culture and Arts (Ed.) Ancestor Worship in Contemporary Society. pp. 163-170. Hanoi: Culture and Information Publisher.

[7] Kleinen, J. (2007). Vietnamese villages facing the future revives the past. Da Nang: Danang publisher.

[8] Vu Khieu (1996). The Hung King with a hundred of families - responsibility for the clans with the immediate task". Origins, Vol.1. pp.7-9. Hanoi: Vietnam Association of UNESCO Clubs

[9] Bui Thi Hoa (2013). The tradition of filial piety in ancestor worship of Vietnamese families in the South of Vietnam. Beliefs of Ancestor Worship in Contemporary Society, pp. 288-298. Vietnam Institute of Culture and Arts. Hanoi: Culture and Information publisher

[10] Le Duc Hanh (2013). Origin of ancestor worship in Vietnamese people. Beliefs of Ancestor Worship in Contemporary Society, pp. 237-247. Vietnam Institute of Culture and Arts. Hanoi: Culture and Information Publisher.

[11] Nguyen Van Huyen (2005). Vietnamese civilization. Hanoi: Literary Association Publisher.

[12] Nguyen Thua Hy (2011). Vietnamese traditional culture, a perspective. Hanoi: Information and communication Publisher.

[13] Luong Van Hy (1994). Economic reform and ritual enhancement in two villages in Northern Vietnam (1980-1990). Challenges on the path of reform in Indochina. pp. 437-481. Harvard University. Hanoi: National Politics Publisher.

[14] Luong Van Hy (2013). Death anniversary of ancestors and socio-economic moves. Comparative analysis of rural communities in the North and the South of Vietnam. Beliefs of ancestor worship in contemporary society, pp. 344-361. Vietnam Institute of Culture and Arts. Hanoi: Culture and Information Publisher.

[15] Nguyen Hoi Loan (2006). Faith in ancestor worship of Vietnamese people. Journal of Psychology, 4 (85), April 2006, pp. 16-19.

[16] Vu Tu Lap et al. (1991). Culture and residents of the Red River Delta. Hanoi: Social Science Publisher.

[17] Bui Phuong Linh (2016). The practice of ancestor worship in suburb areas in the current urbanization conditions. Master's thesis in Sociology. Institute of Social Sciences.

[18] Le Hong Ly (2000). Traditional culture of Dong Ky village. Hanoi: Research Institute of Folk Culture publisher.

[19] Mancacaritadipura, G. (2013). Worship and respect to ancestors in Indonesia: Beliefs and practices, cultural and historical values. Beliefs of Ancestor Worship in Contemporary Society. pp. 181-190. Vietnam Institute of Culture and Arts. Hanoi: Culture and Information Publisher. 
The Tradition of Ancestor Worship in Vietnamese Families from the Beginning to the Present Day and Some Current Problems

[20] Dang Duc Sieu (2006). Vietnamese Cultural Handbook. Hanoi: Literary Publisher.

[21] Cao Van Thanh \& Trinh Thi Thuy (2006). About ancestor worship. Journal of Theoretical Education, 1(106), pp. 56-58.

[22] Dam Thi Uyen \& Nguyen Thanh Thuy (2009). The custom of worshiping in the spiritual life of fishermen on Quan Lan Island, Van Don District, Quang Ninh Province. Journal of Southeast Asian Studies, 6, November 2009, pp. 45-55.

[23] Dang Nghiem Van (2002). Ethnic religious system: ancestor worship (citing the boundary of Hanoi). In O. Tessier (Ed.). Villages in Red River Delta: unsolved problems, pp.49-55. Hanoi: National Center for Social Sciences and Humanities

[24] Salemink, O. (2010). Seeking spiritual security in contemporary Vietnamese society. Modern and the dynamics of tradition in Vietnam: anthropological approaches, Vol.2, pp.1-22. University of Social Sciences and Humanities. HCMC: National University Publisher.

[25] Pham Con Son (2010). Respectable families. Hanoi: The publisher of Culture and Information.

[26] Suenari Michio (2010). How ancestors are pictured on the altar: Comparative analysis with other East Asian societies. Modern and the dynamics of tradition in Vietnam: anthropological approaches, Vol.2. Pp.103-132. University of Social Sciences and Humanities. HCMC: National University Publisher.

Citation: Tran Van Huan. "The Tradition of Ancestor Worship in Vietnamese Families from the Beginning to the Present Day and Some Current Problems" International Journal of Research in Sociology and Anthropology (IJRSA), vol 5, no. 4, 2019, pp. 13-19. doi: http://dx.doi.org/10.20431/2454-8677.0504002.

Copyright: (C) 2019 Authors. This is an open-access article distributed under the terms of the Creative Commons Attribution License, which permits unrestricted use, distribution, and reproduction in any medium, provided the original author and source are credited. 